\title{
Original
}

\section{MORPHOLOGICAL STUDIES ON THE ATTRITION AND MICROHARDNESS OF JAPANESE DECIDUOUS TEETH}

\author{
En-ichiro NISHIHARA*
}

\begin{abstract}
The aim of the present study was to examine the differences in quality between maxillary and mandibular human deciduous teeth. Using the frontal deciduous teeth of Japanese, determination of the attrition, on the basis of newly designed standards, and of the microhardness for teeth which were spontanously dropped, revealed that the attrition of the maxillary teeth was higher than that of the mandibular teeth and that the microhardness of the maxillary teeth was less than that of the mandibular teeth. This finding may suggest some relationship between the trends of dental caries and these factors.
\end{abstract}

Koy words: Attrition, Microhardness, Japanese deciduous teeth

\section{Introduction}

Calculation from the report ${ }^{1)}$ on the survey of dental diseases by the Ministry of Health and Welfare (conducted every 6th year in Japan) since the first in 1957 up to 1981 revealed that dental caries is found more in the maxillary front teeth and in the mandibular molar teeth than in the counterparts of the opposite side in both deciduous teeth and permanent teeth. In the present study, the differences in quality between the maxillary and the mandibular teeth were examined in terms of the attrition and microhardness of Japanese deciduous teeth.

\section{Materials and Methods}

The materials used were the dropped primary teeth of children born in Aichi Prefecture from 1965 to 1975 and who continued living in the same prefecture from birth. The teeth were stored at room temperature, and those with dental caries, remaining tooth stumps, morphological abnormalities, fillings, etc. were excluded from the study. The front teeth and the molar teeth were allowed to grow for more than 3 months and 6 months after birth, respectively, with the same type of nutrition (exclusively either the breast feeding, breast and formula feeding, or bottled feeding).

For the study of the attrition, the teeth were classified by factors of nutrition (the abovementioned three types), type (A B C), position (left and right, maxillary or mandibular) and sex, and a total of 144 teeth were randomly sampled by selecting two teeth each from the materials ( 3 nutrition factors $\times 3$ types $\times$ 4 positions $\times 2$ sexes $\times 2$ teeth). The selected teeth were observed with a stereoscopic microscope at 20 times magnification for the state of attrition between the maxillary and mandibular teeth and compared by nutritional factors. The state of attrition was comparatively examined on the basis of the newly designed standards.

* Department of Dental Research, The National Institute of Health, Tokyo, Japan

* 国立予防衛生研究所画科衛生部

昭和59年 7 月 5 日受付 
For rating the microhardness, only teeth of attrition grades (Table 1) 0 to 2 were used, and the teeth on the following locations were selected from the materials, which were examined according to the following procedures.

I. Three teeth each of female children from the $\frac{\mathrm{C}}{\mathrm{C}} \mid$ region from the 3 nutrition groups, 18 teeth ( 3 teeth $\times 2$ regions $\times 3$ nutritions) in total, were used for the examination. In order to protect the surface of the teeth from damages by the examination steps, each of the teeth was embedded in Quetol-523 $\mathrm{M}$ resin and was polymerized by ultraviolet rays under irradiation with a germicidal lamp $(15 \mathrm{~W})$ at approx. $36^{\circ} \mathrm{C}$ for 48 hours. Then the distal longitudinal face prepared by longitudinal sectioning through the center along the mediodistal line in the direction of the labio (bucco).lingual area was subjected to grinding. The microhardness of the enamel and the dentin was determined with a Vickers hardness tester at a distance of $50 \mu$ from the surface and $100 \mu$ from the enamel-dentin junction. The determination of microhardness was made along the dotted line shown in Fig 1 . This line was made by connecting the crossing point of the assumptive tooth axis (10) with the vertical line (2) to the (10) apex of the pulp chamber, with the apex (3) of the surface layer of the enamel viewed from the line (2).

II. One tooth each from $\frac{E-A}{E-A}$ from the deciduous teeth of female children of the breast-fed group, 10 teeth in total, were subjected to determination of microhardness by the same method as in I . However, the determination with moler teeth was done using a region $100 \mu$ from the surface because the region $50 \mu$ from the surface of the molar teeth was so susceptible to damage that some of the teeth could not be used for the evaluation.

\section{Results}

Attrition: The mean values of the determination were as shown in Table 2, showing no significant difference among the three different types of nutrition in either maxillary or mandibular teeth. How. ever, the grade of attrition of the maxillary teeth was significantly higher than that of the mandibular teeth in each of the three groups.

Microhardness: 1 . The mean values of microhardness in $\frac{\mathrm{C}}{\mathrm{C}} \mid$ were as shown in Table 3. The hardness of the mandibular teeth was significantly higher than that of the maxillary teeth in
Table 1 Standards for the state of attrition of deciduous teeth

$0=$ No attrition was observed.

$1=$ Attrition was noted only in the enamel.

$2=$ Dentin was exposed in the form of a dot or line.

$3=$ Dentin was exposed in the form of a square or circle.

$4=$ The surface could not be identified on the incisal edge or occlusal surface.

(For intermediate states, 0.5 was added to the figure of the lower grade).
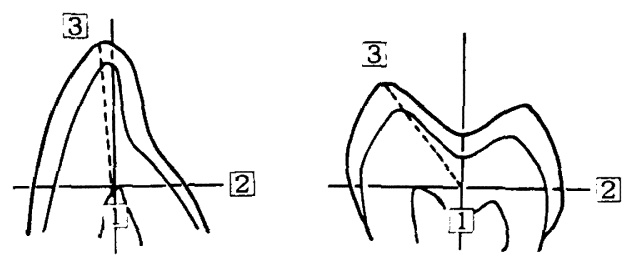

Fig. 1 The determination of microhardness was made along the dotted line. [1 : tooth axis, 20 : line vertical to [1] passing apex of pulp, 3: apex of enamel surface 
Table 3 Microhardness of $\frac{\mathrm{C}}{\mathrm{C}}$

\begin{tabular}{|c|c|c|c|c|}
\hline \multirow{2}{*}{ Nutrition } & \multicolumn{2}{|c|}{ Enamel } & \multicolumn{2}{|c|}{ Dentin } \\
\hline & Maxilla & Mandible & Maxilla & Mandible \\
\hline Breast feeding & $289 \pm 136.3(38)$ & $360 \pm 70.3(40)$ & $74 \pm 10.3(49)$ & $79 \pm 12.0(47)$ \\
\hline $\begin{array}{l}\text { Breast and } \\
\text { formula feeding }\end{array}$ & $318 \pm 42.2(46)$ & $346 \pm 49.6(42)$ & $63 \pm 23.1(63)$ & $73 \pm 13.0(73)$ \\
\hline Bottled feeding & $314 \pm 84.3(44)$ & $365 \pm 47.1(44)$ & $73 \pm 15.0(57)$ & $83 \pm 11.5(62)$ \\
\hline \multicolumn{5}{|c|}{ Mean $\pm \operatorname{SD}(n), 0.01<\mathrm{p}<0.05$} \\
\hline & \multicolumn{2}{|c|}{ Table 4 Microhardness of } & $\frac{E \cdot A}{E-A} \mid$ & \\
\hline & \multicolumn{2}{|l|}{ Enamel } & \multicolumn{2}{|c|}{ Dentin } \\
\hline & Maxilla & Mandible & Maxilla & Mandible \\
\hline A & $283 \pm 44.4(9)$ & $345 \pm 13.3(10)$ & $71 \pm 5.9(15)$ & $76 \pm 8.3(14)$ \\
\hline B & $312 \pm 44.2(12)$ & $398 \pm 34.3(21)$ & $75 \pm 3.6(10)$ & $84 \pm 12.4(18)$ \\
\hline C & $301 \pm 34.8(10)$ & $387 \pm 29.5(11)$ & $75 \pm 10.7(18)$ & $85 \pm 5.1(17)$ \\
\hline $\mathrm{D}$ & $357 \pm 29.0(13)$ & $353 \pm 59.9(13)$ & $54 \pm 9.4(25)$ & $73 \pm 6.7(25)$ \\
\hline E & $295 \pm 30.9(35)$ & $331 \pm 30.7(17)$ & $78 \pm 6.1(24)$ & $85 \pm 14.7(34)$ \\
\hline
\end{tabular}

Mean $\pm \mathrm{SD}(\mathrm{n})$

each group of different nutrition types. As in the case of the attrition, there was no significant difference among the different nutrition groups in terms of microhardness. II. The mean values of microhardness in $\frac{E-A}{E-A}$ were as shown in Table 4. Except for the value of microhardness in the enamel of $D$, the microhardness of the mandibular teeth tended to be higher than that of the maxillary teeth.

\section{Discussion}

The frontal deciduous teeth of the maxilla showed higher grades of attrition than those of the counterparts in the mandible in all the nutrition groups. The same trend was observed also in the results ${ }^{2}$ of a survey on approx. 20,000 deciduous teeth in the Kanto, Tokai and Hokuriku Districts of Japan. However, Tochihara ${ }^{3)}$ and Tsuda' separately reported that the attrition of Japanese frontal deciduous teeth is generally slightly stronger in the mandibular teeth than in the maxillary teeth. On the other hand, calculation of the data by Sugiyamas) revealed that weaker attritions (Table 1, 0-2) were more frequent in the mandibular teeth, while stronger attritions (Table 1, 3 and 4) were found in the maxillary teeth. Goto $\left.^{6}\right)$ reported on the abrasion of teeth confirming a trend similar to that of Sugiyama's report. As with these reports ${ }^{5,8)}$ the mean value of attrition in the present study revealed generally strong grades of attrition in both the maxillary and mandibular teeth, and also stronger attrition of the maxillary teeth than of mandibular teeth. More will have to be studied in the future on the differences in attrition between teeth located on the alveolar bone ${ }^{3,4)}$ and spontaneously dropped teeth ${ }^{2,5,8)}$ as seen in the present study, and also on the difference in the quality of teeth thus collected from varying time periods.

No report has so far been published on the comparison of attrition between maxillary and mandibular deciduous teeth in races other than the Japanese.

Further, I have not reported the determination of the attrition of molar teeth in the present study. Some of the reasons for this are that the number of available teeth was extremely small in comparison with that of front teeth in the present study and that there were hardly any differences in attrition bet- 
ween the maxillary and mandibular teeth. Although still under study, there has been no significant difference noted so far by different factors of nutrition, types of teeth, different regions (left and right) and sexes.

The new design of the grade of attrition of deciduous teeth was derived from the following 4 factors.

i) The following criticism can be made of the reports ${ }^{5 \cdot 18}$ ) on grading attrition by defect area sizes. Namely, if the defect in the teeth extends beyond the incisal edge, it is occasionally difficult to judge whether or not any disease other than attrition (such as, trauma, abrasion by brushing ${ }^{14)}$, initial caries, etc.) is involved.

ii) Explanation of grade 4 of attrition in the classification of incisal edges of permanent teeth ${ }^{15}$ ) was inadequate conconcerning deciduous teeth.

iii) In the detailed classification of deciduous teeth ${ }^{3,5}$, there are too many items to allow checking a large number of deciduous teeth. On the other hand, an overly simplified classification ${ }^{10)}$ or a classifi. cation without " no attrition" ${ }_{17}$ ) would not be suitable to calculate the mean grades on the basis of the total of the grades of attrition.

iv) Observations ${ }^{18-21)}$ on the roughness or trifling injuries on the surface are based only on limited ranges, and would not be suitable for comparative examination with the range covering the enamel and dentin.

In the examination of microhardness, a converse trend was observed from that of attrition, in that the microhardness of the mandibular front teeth was higher than that of the maxillary front teeth. Also from calculations based on the survey') by the Ministry of Health and Welfare, more dental caries were observed in the maxillary front teeth than in the mandibular front teeth. Therefore, only from the figures in the results, it can be said that the variations in the numbers of dental caries and in the attrition are identical between the maxillary and the mandibular frontal deciduous teeth, whereas the variations in the numbers of dental caries and the microhardness show a converse trend in the maxilla and the mandible. Therefore, there may be some correlation among the microhardness, attrition, and the number of dental caries. However, the microhardness of the transparent layer of teeth is occasionally lower than that of the sub-transparent layer ${ }^{22,23)}$ contrary to previous expectation. Therefore, it would not be enough to only refer to the previous reports ${ }^{24-28}$ in studying the relationship among the microhardness, attrition and dental caries, and more experiments are necessary from diverse and systematic viewpoints.

The parts for determination of microhardness in the present study were selected in such a manner that as many determination counts as possible would be available. The reason for this was that, although the transition of microhardness from the surface into the deep layers in the enamel was not smooth, probably due to the use of spontaneously dried teeth as material, the trend of decline of the microhardness was invariable in all parts of the teeth.

The microhardness of the E-A region (Table 4) was not subjected to evaluation on the significance of the data because the number of the available samples was limited. Also in this microhardness, as in the attrition, there was no significant difference among the different factors of nutrition, types of teeth, different regions, and sexes.

No significant differences among the nutrition groups were observed in either side of the jaws in terms of the attrition and microhardness. This may be attributable to the fact that the periods of time for growth with the same nutrition were less than the time ${ }^{29)}$ needed for the completion of the tooth crown. 


\section{Acknowlegement}

I thank Mr. T. Nagai (Lab of Technology, NIH, Japan) for lending me some of the deciduous teeth and the Vickers hardness tester.

\section{References}

1) Division of Dental Health, Medical Affairs Bureau, Ministry of Health and Welfare, Japan: Report on the survey of dental diseases (1957, 1963, 1969). (1981), Kohkuh hoken kyohkai, Tokyo, First ed., (1982), (1983), (p. 48, 50, 52-54, 56, 66-68, 70, $96,97)$. (p. $48-53,83,86,89,101$ ). in Japanese $(\mathrm{J})$

2) Nishihara, E. and Nagai, T. : Attrition and Microhardness, Annual reports of NIH Tokyo Japan., 36 ; 390-391, 1983. (J)

3) Tochihara, H.: Studies on the abrasion from mastication of the Japanese, Kumamoto igattsukai zasshi., 31(Suppl 4) ; 607-656, 1957. (J)

4) Tsuda, M.: A statistical studies on the abrasion of teeth according to age, Kohtsuh igaku., 8(4); 41-43, 1956. (J) with English Summary (E)

5) Sugiyama, K.: A Morphological Study of the Japanese Deciduous Teeth by Measurement, Aichi-gakuin. J. Dent. Sci., 7(2 - 3) ; 149-180, 1969. (JE)

6) Gotoh, S.: Physical Anthropological Study of Deciduous Anterior Teeth in Modern Japanese, J Kyushu Dent Soc., 37(2) ; 413-428, 1983. (JE)

7) Broca, M. P.: Instruction générales pour les Recherches Anthropologiques a faire sur le vivant, G. Masson libraire de l'academie de medecine, Paris, 2. éd., 1879, p. 221247.

8) Leigh, R. W.: Dental Pathology of the Eskimo, Dental Cosmos., 67;884-898, 1925.

9) Martin, R.: Lehrbuch der Anthropologie in systematischer Darstellung, Verlage von Gustav Fischer, München, erster Bd., 1928, p. 204-231.

10) Yamada, E. : Nihonjin-siga no mametsu to nenreiteki kankei ni oite, Kanazawa idai juhzenkaishi., 36 ; 456-468, 1931. (J)

11) Gustafson, G. : Age determinations on teeth, J. A. D. A., 41;45-54, 1950.

12) Davies, T. G. H. and Pedersen, P. O.: The Degree of Attrition of the Deciduous Teeth and First Permanent Molars of Primitive and Urbanised Greenland Natives, Brit. B. Dent. J., 99 ; 35-43, 1955.

13) Lysell, L.: Qualitative and quantitative determination of attrition and the ensuing tooth migration, Acta Odont. Scand., 16 ; 267292, 1958.

14) Bergstrom, J. and Lavstadt, S. : An epidemiologic approach to tooth brushing and dental abrasion, Community Dent. Oral Epidemiol., 7(1) ; 57-64, 1979.

15) Amano, J.: Mdico-legal Studies on Human Teeth, Nihon Hoigaku Zasshi., 5(5) ; 170186, 1951. (J)

16) Katsuyama, H. : A Morphological Study on the Attrition of Primary Molars Restored with Composite Resin, Tsurumi Univ. Dent. J., 10(1); 75-119, 1984. (JE)

17) Goldstein, M. S. : Caries and attrition in the molar teeth of the eskimo mandible., Amer. J. Phys. Anthrop., 16(4) ; 421-430, 1932.

18) Ryan, A. S.: A Preliminary Scanning Electron Microscope Examination of Wear Striation Direction on Primate Teeth, J. Dent. Res., 58(1) ; 525-530, 1979.

19) Davis, W. B. and Winter, P. J.: The Effect of Abrasion on Enamel and Dentine after Exposure to Dietary Acid, Brit. Dent. J., 148(1l and 12) ; 253-256, 1980.

20) Covert, H. H. and Kay, R. F. : Dental Microwear and Diet: Implications for Determining the Feeding Behaviors of Extinct Primates, With a Comment on the Dietary Pattern of Sivapithecus, Am. J. Phys. Anthropol., 55 ; 331-336, 1981.

21) $\mathrm{Ai}, \mathrm{M}$. and Yamamoto, A.: Jaw function and attrition of the occlusal surface, Dental outlook., 62(4); 669-678, 1983. (J).

22) Ogawa, K., Yamashita, Y., Ichijo, T. and Fusayama, T.: The Ultrastructure and Hardness of the Transparent Layer of Human Carious Dentin, J. Dent. Res., 62(1) ; 7-10, 1983.

23) Yamada, T., Nakamura, K., Iwaku, M. and Fusayama, T.: The Extent of the Odontoblast Process in Normal and Carious Human Dentin, J. Dent. Res., 62(7) ; 798-802, 1983.

24) Yamamoto, Y.: An in vir'o Study on the 
Remineralization of Inner carious DentinThe Remineralization Effect of Glass Ionomer Cement-, Tsurumi Univ. Dent. J., 10 (1) ; 57-74, 1984. (JE)

25) Featherstone, J. D. B., ten Cate, J. M., Shariati, M. and Arends, J.: Comparison of Artificial Caries-Like Lesions by Qunatitative Microradiography and Microhardness Profiles, Caries Res. 17 ; 385-391, 1983.

26) Arends, J., Schuthof, J. and Jongebloed, W. G.: Microhardness Indentations on Artificial White Spot Lesions, Caries Res., 13 ; 290-297, 1979.
27) Davidson, C. L., Hoekstra, I. S. and Arends, J. : Microhardness of Sound, Decalcified and Etched Tooth Enamel Related to the Calcium Content, Caries Res., 8 ; 135-144, 1974.

28) Nihei, I. : A Study on the Hardness of Human Teeth Part III. Hardness of caries teeth and attrited teeth, J. Osaka Univ. Dent. Soc., 4(2) ; 182-192, 1959. (JE)

29) Schour, I. and Massler, M. : The growth pattern of the human teeth, J. A. D. A., 27 (12) ; 1918-1931, 1940.

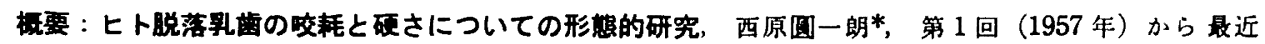

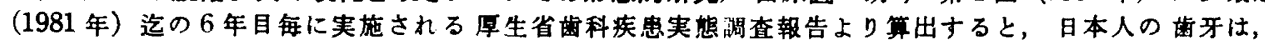

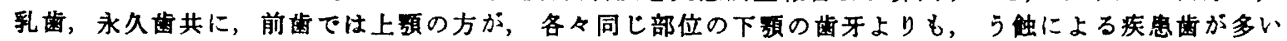
傾向である。この傾向が何に起因しているのか，未だ明確ではないものと思われる。そこで今回，上頻 と下頻の歯罂の差異を, まず，日本人脱落乳歯の咬耗と硬度の検索を通して探ってみたものである。方 法は，対象とした脱落乳落を新たに考案した咬耗基準度で分類するとともに，切断面を硬度計で測定し

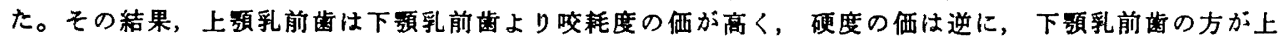

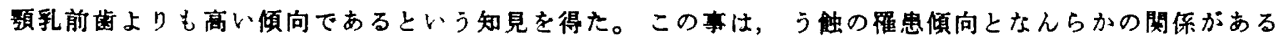
のか子知れない。

索引用語 : 咬耗度, 硬度, ヒト脱落乳齿 